\title{
Erratum to: Optimization of Ultrasonic-Assisted Extraction of Polyphenols, Anthocyanins, and Antioxidants from Raspberry (Rubus coreanus Miq.) Using Response Surface Methodology
}

\author{
Hui Teng • Won Y. Lee • Yong H. Choi
}

Published online: 2 July 2014

(C) Springer Science+Business Media New York 2014

Erratum to: Food Anal. Methods

DOI 10.1007/s12161-013-9786-2

Authors want to apologize for an error in the equation of total anthocyanin content (TAcyC) calculation in the above paper. The correct equation is as follows:

$\operatorname{TAcyC}(m g C G E / g d w)=\Delta A \times M \times \mathrm{DF} \times 10^{3} / \varepsilon \times \mathrm{W}$

The online version of the original article can be found at http://dx.doi.org/ 10.1007/s12161-013-9786-2.

H. Teng $\cdot$ W. Y. Lee $\cdot$ Y. H. Choi $(\bowtie)$

School of Food Science and Bio-Technology, Kyungpook National

University, 1370-Sankyunk Dong, Puk Gu, Daegu 702-701,

Republic of Korea

e-mail: yhechoi@knu.ac.kr

W. Y. Lee $\cdot$ Y. H. Choi

Food and Bio-Industry Research Institute, Kyungpook National

University, Daegu 702-701, Republic of Korea 